\title{
VARIATION IN WILD POPULATIONS OF PAPAVER DUBIUM
}

\author{
III. THE GENETICS OF STIGMATIC RAY NUMBER, HEIGHT AND \\ CAPSULE NUMBER
}

\author{
M. J. LAWRENCE \\ Department of Genetics, The University, Birmingham, 15
}

Received 1.iv.71

\section{INTRODUGTION}

Previous papers in this series have been concerned with an analysis of the genetics of flowering time in natural populations of Papaver dubium (Lawrence, $1965,1969)$. In the present paper we are concerned with a similar analysis of three further metrical characters, for which the material previously described was also scored. The extension of this inquiry to several characters requires little general justification, for it must strengthen the inferential basis of any conclusions that we may wish to draw about the population genetics of the species. It is perhaps worth pointing out, however, that there is a special reason for doing so here, in view of the role which flowering time could play in the determination of the mating system within a population.

Little is known about the ecology of this species, so that it has not so far been possible to choose traits on the basis of their known adaptational importance to the species. The traits have, therefore, been chosen primarily for their technical convenience, though each also has some intrinsic biological interest. Stigmatic ray number, for example, corresponds exactly, both numerically and spatially, to the number of septae which divide the internal volume of the gynaecium and on which the ovules are borne. The number of seeds produced by a capsule could, therefore, be a function of this number. Then again, the frequency with which poppies are found growing in quite dense vegetation in natural habitats (and previously in cereal crops) suggests that stature could be an important trait with respect to the competitive ability of the species relative to that of others. The third trait with which we are concerned here requires little comment, for capsule number provides an obvious crude measure of fitness.

\section{Materials and methods}

The structure of the two main experiments from which the present data were obtained has been described in detail elsewhere (Lawrence, 1969). Briefly, both experiments concern the families of a $20 \times 20$ partial diallel design which comprises five sets of $4 \times 4$ intrapopulation and four sets of $5 \times 5$ interpopulation diallel crosses. All four sets of the interpopulation families were grown in the first experiment, but only two in the second, all intrapopulation families being grown in both experiments.

Stigmatic ray number was scored as the average number of the first three flowers to open on each plant in 1959 and of the first five in 1960, as this trait is not constant within a plant. Height was measured (in centimetres) in the usual way, from ground level to the top of the highest capsule on each plant at the end of the season. The number of capsules borne by each plant 
was also scored at this time. All four metrical characters were recorded in the first experiment, but only flowering time and ray number in the second.

\section{Results}

\section{(i) Correlation between characters}

The way in which variation with respect to one character may be associated with that of another is of interest chiefly because of the insight it can provide about the different effects of selection in different populations of the species. This is a matter which we shall consider elsewhere, however, for the present data is unsuitable for this purpose, because of the genetical relationships between the families of a set of diallel crosses. For the present, our interest in the way that the characters are related is restricted to the question of whether we may regard them as sufficiently independent to make discussion of each on its own worth while. If any pair of characters are not at least partially uncorrelated, there is clearly little to be gained by continuing to consider them both.

The data of the intrapopulation diallel crosses raised in the first experiment have been examined with this question in mind. The total phenotypic variation for each trait was partitioned into two items, one concerning differences between and another differences within the individual diallel progenies. The sums of squares of this partition are, respectively, the Total (between families) and the Duplicate plots items of the diallel analysis of variance we shall be considering shortly (see, for example, table 3). Taking each trait in turn, these sums of squares were then adjusted for concomitant variation with each of the remaining traits by the usual analysis of covariance methods. With two exceptions only, this adjustment did not result in the elimination of heritable variation for any trait in any population, in which it had been possible to detect such variation prior to adjustment. It appears, therefore, that there is no evidence in the present data of any consistent correlation between the four characters scored in the experiment. It is worth pointing out, however, that this method of the investigation of correlation between characters would cause one to conclude that a pair of characters should effectively be regarded as a single character only if they were highly correlated. This is, of course, exactly the situation we wish to avoid. The method is, therefore, an appropriate one for our present purpose.

\section{(ii) Stigmatic ray number}

The average scores of the families grown in the first experiment are shown in table 1 and those of the second experiment in table 2. The ray numbers shown in these tables are similar to those observed in natural populations by Clapham, Tutin and Warburg (1962), McNaughton and Harper (1964) and by ourselves. The analysis of these data is conveniently considered in two parts. We shall look first at the analysis of the intrapopulation families (table 3) and then at that of the interpopulation progenies (tables 4 and 5). The sampling variance of the scores (the Duplicates item) turns out to be homogeneous over populations, seasons and sets, despite the fact that the scores are averages of three capsules in 1959 and of five in 1960. The analysis of variance used is that of Hayman (1954) and Jones (1965).

Turning, then, to the analysis of the intrapopulation data (table 3), there is no doubt, firstly, that stigmatic ray number is a heritable character, for 


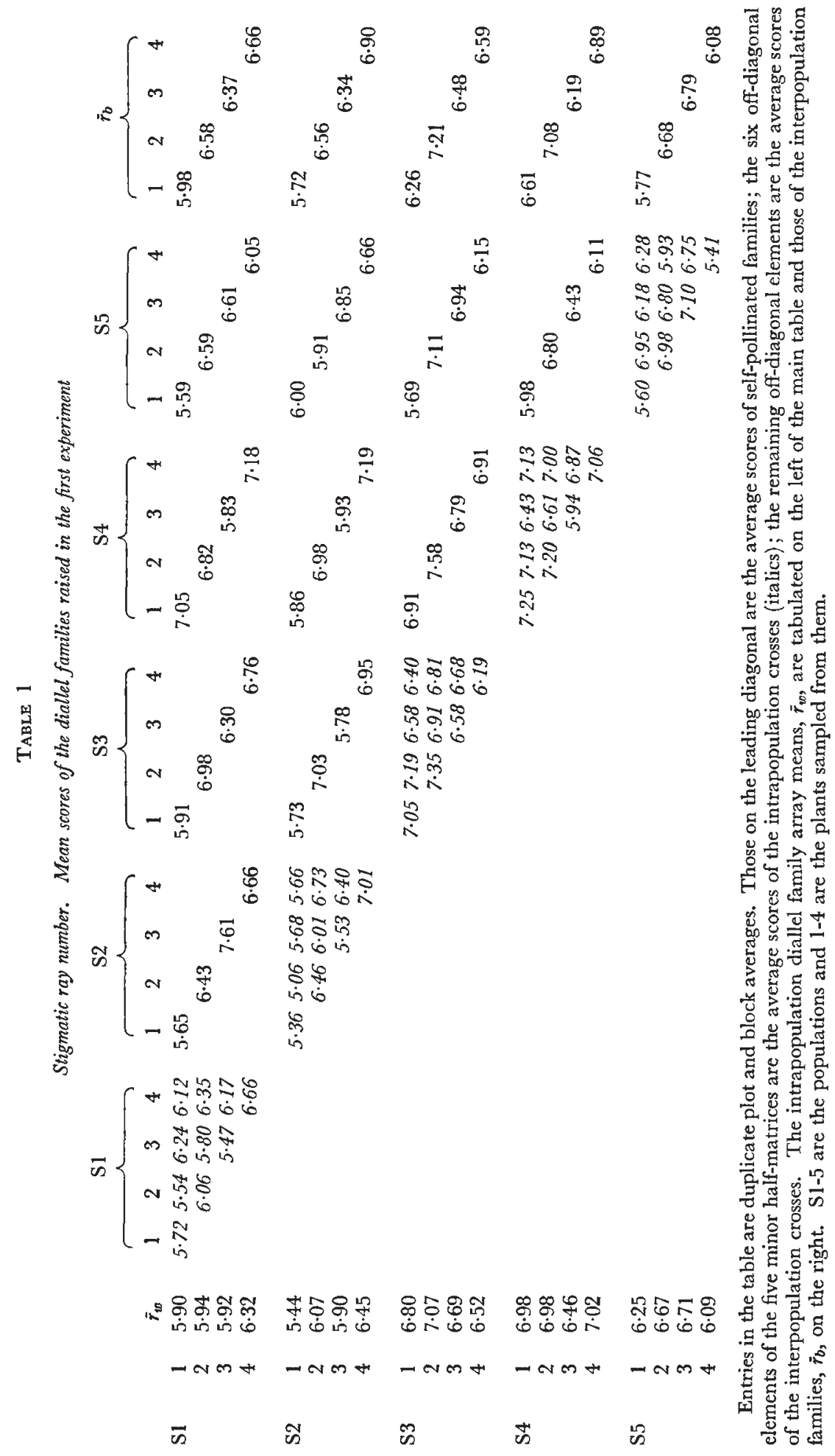




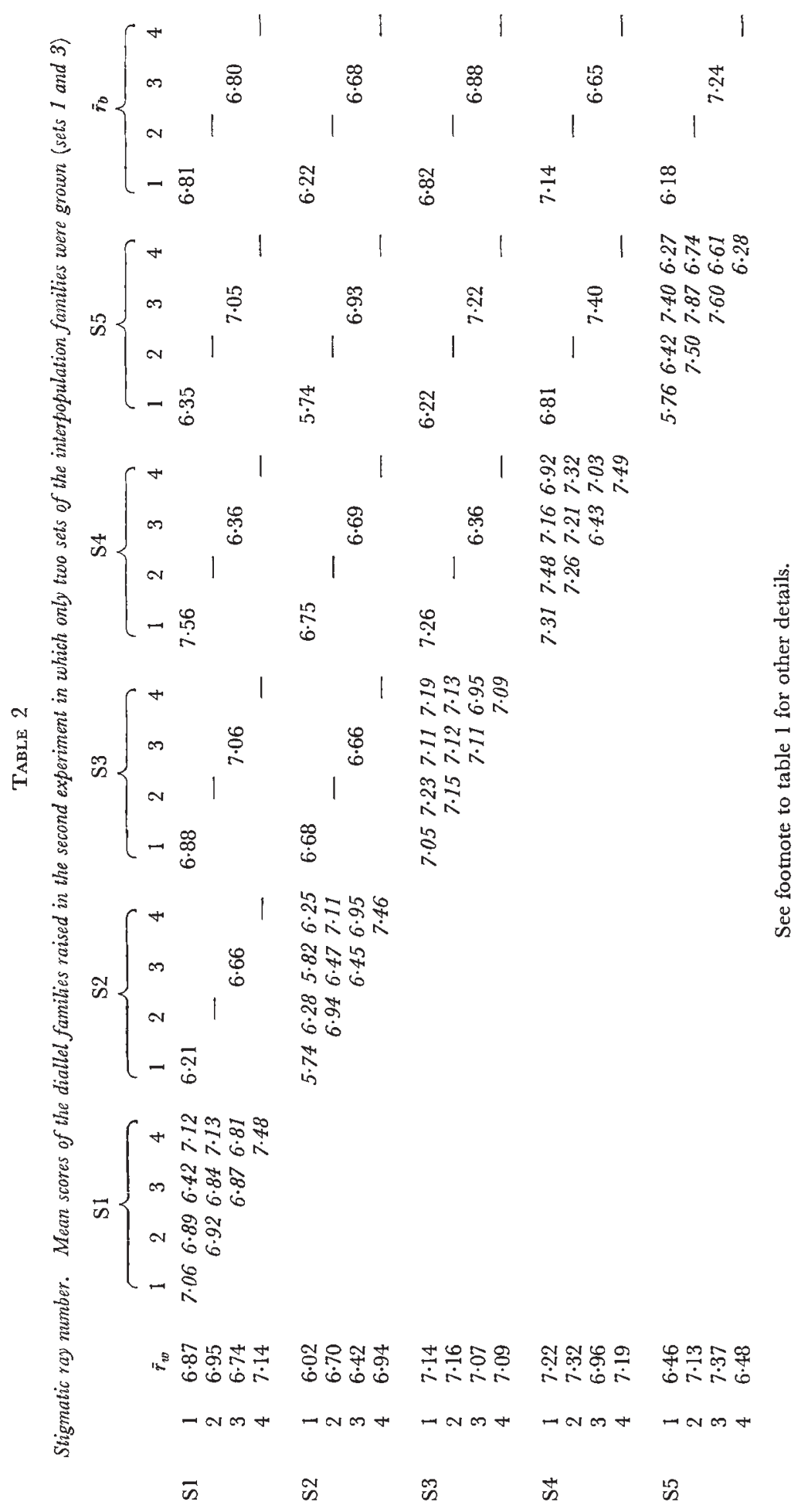


TABLE 3

Stigmatic ray number. Analyses of variance of the intrapopulation diallel families

\begin{tabular}{|c|c|c|c|c|c|c|}
\hline \multirow[b]{2}{*}{ Source } & \multirow[b]{2}{*}{ d.f. } & \multicolumn{5}{|c|}{ Population } \\
\hline & & S1 & $\mathrm{S} 2$ & S3 & S4 & S5 \\
\hline$a$ & 3 & $1 \cdot 60 * * *$ & $7 \cdot 42 * * *$ & $0.83 * * *$ & $2 \cdot 44 * * *$ & $7 \cdot 65 * * *$ \\
\hline$b_{1}$ & 1 & $0 \cdot 11$ & $0.53 *$ & 0.00 & 0.02 & 0.46 \\
\hline$b_{2}$ & 3 & 0.02 & 0.33 & 0.02 & $0 \cdot 23$ & 0.42 \\
\hline$b_{3}$ & 2 & $0 \cdot 14$ & $0 \cdot 24$ & 0.06 & $0 \cdot 13$ & 0.24 \\
\hline Total (between families) & 9 & $0.59 * * *$ & $2 \cdot 70^{* * *}$ & $0.29 * *$ & $0.92 * * *$ & $2 \cdot 79 * * *$ \\
\hline Years & 1 & $17 \cdot 79 * * *$ & $6 \cdot 22 * * *$ & $2 \cdot 32 * * *$ & $1 \cdot 78 * * *$ & $4.00 * *$ \\
\hline Blocks (within years) & 2 & $1 \cdot 32 * * *$ & $0.53 *$ & $0.42 *$ & 0.39 & 0.95 \\
\hline Years $\times a$ & 3 & 0.08 & 0.03 & $0.53 * *$ & $0 \cdot 15$ & $0 \cdot 27$ \\
\hline Years $\times b_{1}$ & 1 & 0.37 & $0 \cdot 00$ & 0.01 & 0.02 & 0.05 \\
\hline Years $\times b_{2}$ & 3 & $0.39 *$ & 0.26 & $0 \cdot 11$ & $0 \cdot 24$ & 0.40 \\
\hline Years $\times b_{3}$ & 2 & 0.37 & $0.40 *$ & $0 \cdot 14$ & $0 \cdot 12$ & $1 \cdot 85 *$ \\
\hline Years $\times$ Total & 9 & 0.28 & $0 \cdot 19$ & $0.25 *$ & $0 \cdot 16$ & 0.64 \\
\hline Block interactions & 18 & $0 \cdot 16$ & $0 \cdot 13$ & 0.07 & 0.12 & $0.38 *$ \\
\hline Duplicate plots & 40 & $0.13(38)$ & $0 \cdot 11$ & $0.10(32)$ & 0.10 & $0.16(39)$ \\
\hline Grand total & 79 & $0.47(77)$ & 0.50 & $0.17(71)$ & 0.23 & $0.64(78)$ \\
\hline
\end{tabular}

Entries in the table are mean squares whose significance is indicated in the conventional manner. The designed number of degrees of freedom for each item in the analysis are shown in the column on the left. The entries in brackets show the number of degrees of freedom of those items where, due to losses, this number is less than the designed one.

TABLE 4

Stigmatic ray number. Analysis of variance of the interpopulation diallel family data of the first experiment

Source

$a$
$b_{1}$
$b_{2}$
$b_{3}$

Total (between families)

Sets

Blocks

Sets $\times a$

Sets $\times b_{1}$

Sets $\times b_{2}$

Sets $\times b_{3}$

Sets $\times$ Total

Block interactions

Duplicate plots

Grand total d.f.

$43 \cdot 32 * *$

10.64

$40.56 *$

$5 \quad 0.64 * *$

$14 \quad 1 \cdot 38 * * *$

$35 \cdot 82 * * *$

$1 \quad 1.51 * *$

$12 \quad 2 \cdot 66 * * *$

$30.72 * *$

$12 \quad 0.41 * *$

$15 \quad 0.81 * * *$

$42 \quad 1 \cdot 22 * * *$

$59 \quad 0.21$

$119 \quad 0.17$

$238 \quad 0.51$ 
there is unambiguous evidence of genetical variation in each of the five populations examined. Secondly, most of this variation can be ascribed to the additive effects of the genes concerned, such evidence of dominance as there is in this pooled data, being confined to S2. Though the $b_{1}$ item of the analysis of this population is only just significant, there are, as we shall see later, further reasons for taking this evidence seriously. Thirdly, though the scores obtained from the second experiment are a little higher, on average, than those from the first, there is little evidence, with the possible exception of S3, that genotype-environment interaction is an important source of variance for this trait.

\section{TABLE 5}

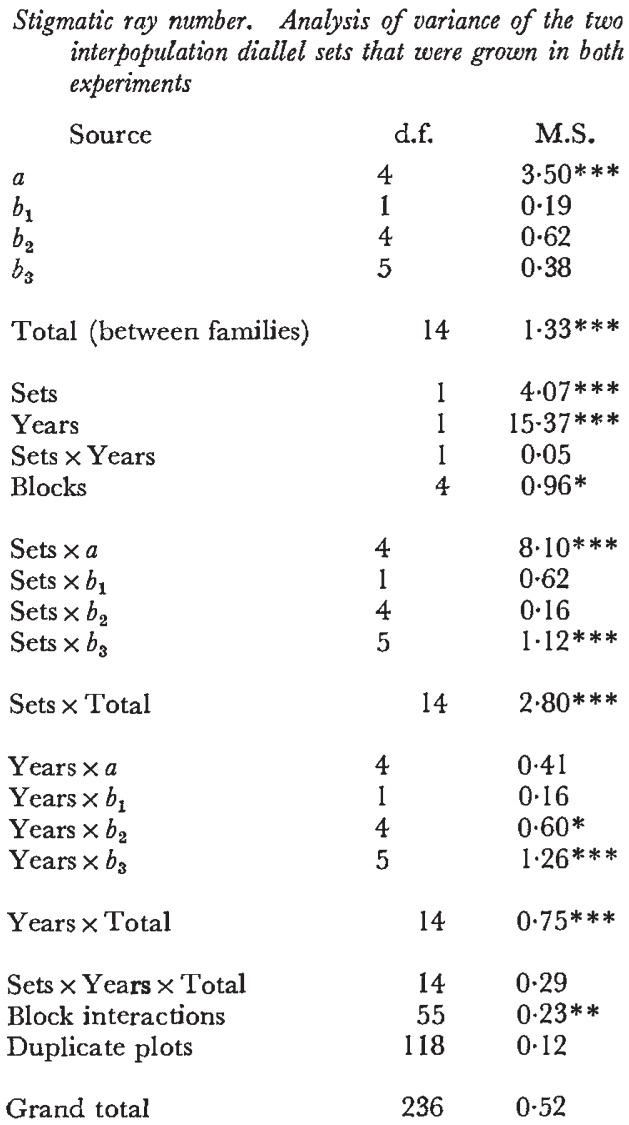

With these conclusions in mind, we may turn next to the analysis of the interpopulation data. This too falls into two parts. We recall that four sets (i.e. genetical replicates) of diallel families were grown in the first experiment, but only two in the second. The analysis of the first season's data is shown in table 4 and that concerning the two sets which were raised in both seasons, in table 5. These analyses are not, of course, independent, for both concern the two sets grown in both seasons.

The significance of the $a$ mean square in both of these tables is expected in view of the outcome of the intrapopulation analysis. In the same way, 
we expect to find that there are significant differences between sets, both on average (the Sets item), as well as in respect of the principal genetical effects of this analysis (e.g. the Sets $\times a$ mean square). Such differences are, of course, a reflection of those we detected previously in the analysis of the intrapopulation families. Nevertheless, these interaction items of the interpopulation analysis provide a means of asking whether the genetical variation concerning differences between populations is any greater than that concerning differences within them. For ray number it is not, for the $a$ mean squares are not significantly greater than their corresponding Sets $\times a$ mean squares in either table. Thus, though each of the populations examined here is polymorphic for ray number, the mean expression of the trait is similar in all (note that, following Barnes and Kearsey (1970), we are using the term genetical polymorphism in a wider sense than Ford (1940) originally defined it).

The presence of non-additive differences in these interpopulation data, in view of their paucity in the intrapopulation families, is less expected. Two points must be borne in mind, however, in considering this apparently anomalous outcome. First, the detection of dominance in a multiple-mating design is never easy and ideally requires an experiment which is appreciably larger than the present one (Kearsey, 1970). Because of this, while we can be reasonably confident about the presence of dominance in material where the appropriate mean squares are significant, we are unable to argue the converse convincingly, namely, that its absence may be inferred when these mean squares are not significantly greater than their sampling variance.

The second point concerns the nature of the genetical effects which the present analysis can detect. These are, of course, the effects of genes in interpopulational or non-coadapted combinations. Gene action in such heterozygotes need not be, and demonstrably often is not, the same as that concerning the co-adapted combinations whose action can be examined in intrapopulational families. Furthermore, some of the loci concerned, whose segregation may be detected in interpopulation crosses, may be fixed within a population so that their effects cannot be assayed in intrapopulation material. Indeed, in situations where it is possible to show that the genetics of interpopulation crosses differs from that of intrapopulation crosses, we may be sure that the populations concerned have undergone independent evolution, irrespective of whether this genetical divergence has been accompanied by changes in the mean expression of the trait or not.

In the present circumstances, however, the presence of non-additive variance in the interpopulation material must be ascribed to the presence of this type of variance in the $\mathrm{S} 2$ population. Reanalysis of the interpopulation diallel progenies, having excluded those with an S2 parent, causes the virtual elimination of non-additive variance, though additive variance remains undiminished. For this reason, the dominance that we were able to detect in the S2 families appears to be genuine, though we cannot be sure that its manifestation has not been enhanced in interpopulation heterozygotes. This dominance is incomplete and acts in the direction of low stigmatic ray number. $W r / V r$ analysis (Jinks, 1954; Dickinson and Jinks, 1956) of these S2 families shows that parent 1 possesses the greatest and parents 2 and 4 the least number of dominant alleles.

The significance of the Years $\times b_{3}$ item in table 5 invites a reappraisal of the previous conclusion concerning genotype-environment interaction in this material. On this, interpopulation, evidence the trait is somewhat less 
stably expressed over environments than was thought earlier. Any conclusion that we might wish to draw about the implications of the variation we have detected in these laboratory experiments in respect of the natural environment, must, in consequence, be circumspect.

\section{(iii) Height}

We recall that height and capsule number were scored in the first experiment only. The average scores of the diallel families are shown in table 6 and the analysis of these data in tables 7 and 8 . The heights shown in table 6 fall well within the range observed in natural populations.

Inspection of table 6 suggests that the populations are relatively homogeneous as regards their stature, with the exception of Sl only. Indeed, with the exception of S2, there is little evidence of genuine heritable variation within these populations either (table 7). The analysis of the interpopulation families (table 8), on the other hand, leaves no doubt about the presence of additive variance in these data. Furthermore, this can be shown to be chiefly due to differences between, rather than differences within, these populations in two ways. First the ratio of the $a$ to the Sets $\times a$ mean square of the interpopulation analysis is both large and significant $(F=7 \cdot 85$, $\mathbf{P}=0.01-0.001)$. Secondly, a reanalysis of the interpopulation data, having first excluded those progenies with an $\mathrm{Sl}$ parent, reduces the $a$ mean square to a value $(12.03)$ which is no longer significantly greater than its sampling variance.

Height appears, therefore, to be a trait, in contrast to stigmatic ray number, for which these populations differ more in respect of their means than for variation about these means; i.e. it is a trait that has been subjected to directional selection.

The interpretation of the non-additive effects in these data is, once again, less straightforward. The significance of the $b_{1}$ item in table 8 is a reflection of the fact that the interpopulation hybrids are a little taller than their selfed collaterals, a difference which, in other circumstances might be regarded as evidence of inbreeding depression. The significance of the Sets $\times b_{3}$ item of this table suggests, furthermore, that the sets are heterogeneous with respect to their non-additive effects. Yet there is no real evidence of genuine non-additive variation in any of the intrapopulation data, for the $b_{2}$ item of the $\mathrm{Sl}$ analysis can scarcely be accepted at its face value in the absence of any evidence of additive variance in this population. The occurrence of this anomalous item does, however, raise the question of whether it is the cause of the heterogeneity between sets. Reassuringly, it is not, for both the $b_{1}$ and the Sets $\times b_{3}$ items of the analysis mentioned earlier (Sl progenies excluded), though diminished, nevertheless remain significant.

Now we saw earlier that in $\mathrm{S} 2$ alone was it possible to detect any heritable variation. It is, therefore, worth inquiring whether the genetic differences within this population are the cause of the significant interaction item of table 8, despite the fact that we have no evidence of non-additive effects within the same population. This appears to be the case. A reanalysis of the interpopulation data, having excluded those progenies with an S2 parent, brings about complete homogeneity of the sets with respect to their non-additive properties. Our inability to detect the latter in the S2 analysis itself must, therefore, be a consequence of the small size of the intrapopulation diallels. 


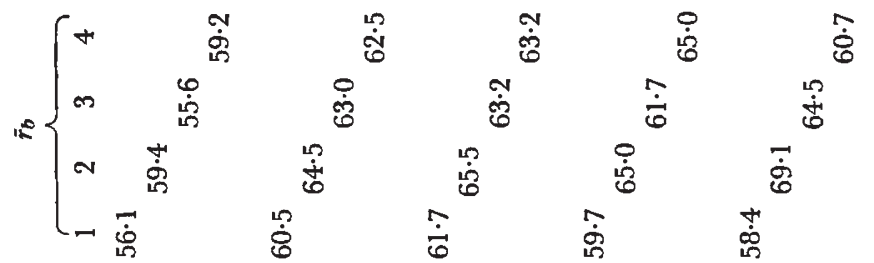

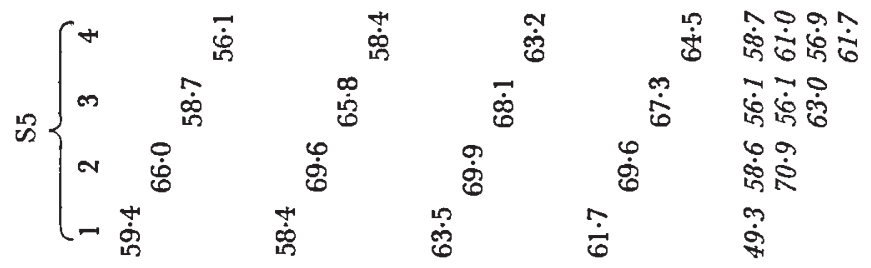

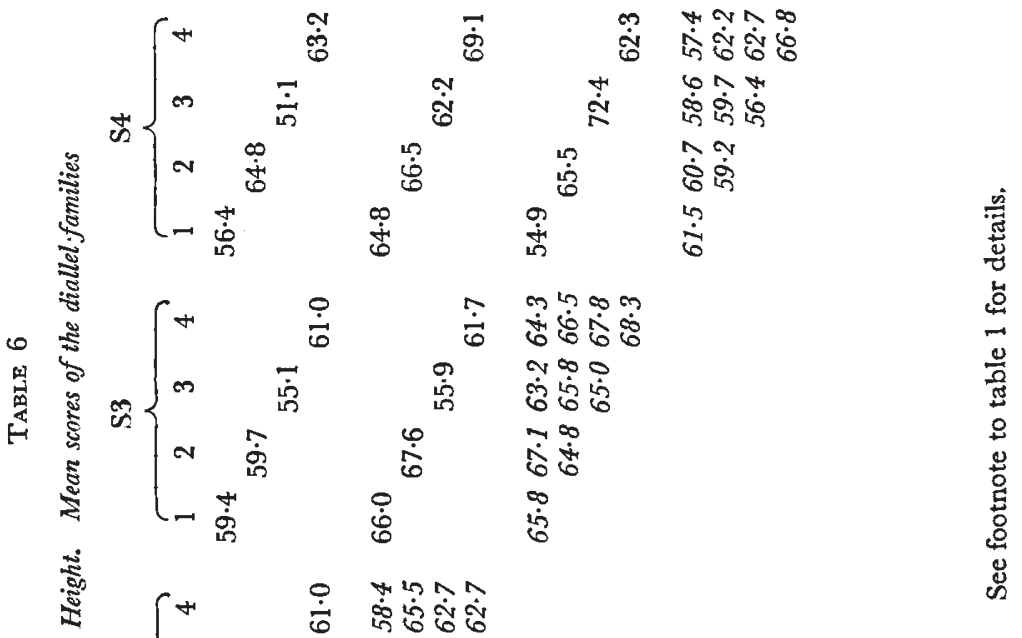

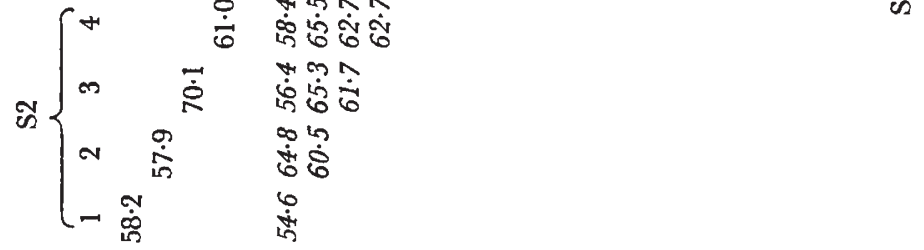

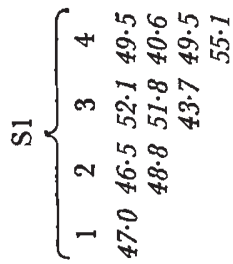

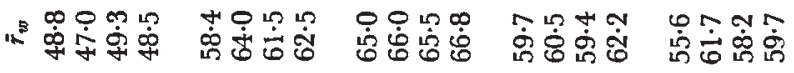

$$
\begin{aligned}
& \text {-Nmt -Nmt TNma TNath TNmt } \\
& \text { के ชै है मे है }
\end{aligned}
$$


This reanalysis of the interpopulation data reveals two further features of the genetics of height in this material. First, despite the exclusion of S2 progenies, some evidence of additive differences within sets remains, for the Sets $\times a$ item is still significant. It is thus difficult to escape the conclusion

TABLE 7

Height. Analyses of variance of the intrapopulation diallel families

\begin{tabular}{|c|c|c|c|c|c|c|}
\hline \multirow[b]{2}{*}{ Source } & \multirow[b]{2}{*}{ d.f. } & \multicolumn{5}{|c|}{ Population } \\
\hline & & $\mathrm{S} 1$ & $\mathrm{~S} 2$ & S3 & $\mathrm{S} 4$ & $\mathrm{~S} 5$ \\
\hline$a$ & 3 & $19 \cdot 80$ & $99 \cdot 14 * *$ & $12 \cdot 00$ & $59 \cdot 73$ & $234 \cdot 72$ \\
\hline$b_{1}$ & 1 & 0.65 & $51 \cdot 54$ & $0 \cdot 26$ & $3 \cdot 74$ & $104 \cdot 30$ \\
\hline$b_{2}$ & 3 & $170 \cdot 28 * *$ & $42 \cdot 89$ & $8 \cdot 32$ & $33 \cdot 02$ & $105 \cdot 14$ \\
\hline$b_{3}$ & 2 & $39 \cdot 80$ & $15 \cdot 54$ & $16 \cdot 83$ & $20 \cdot 90$ & $3 \cdot 48$ \\
\hline Total (between families) & 9 & $72 \cdot 30 * *$ & $56 \cdot 50 *$ & $10 \cdot 51$ & 35.99 & $125 \cdot 65$ \\
\hline Blocks & 1 & $127 \cdot 32$ & $57 \cdot 60$ & $17 \cdot 42$ & $62 \cdot 57$ & $4 \cdot 06$ \\
\hline Block interactions & 9 & $48 \cdot 57$ & 23.93 & 14.71 & $19 \cdot 50$ & $139 \cdot 84 *$ \\
\hline Duplicate plots & 20 & $20 \cdot 12(19)$ & 19.09 & $23 \cdot 80(16)$ & $23 \cdot 87$ & $55 \cdot 60$ \\
\hline Grand total & 39 & $42 \cdot 05(38)$ & $29 \cdot 80$ & $17 \cdot 87(35)$ & $26 \cdot 64$ & $89 \cdot 85$ \\
\hline
\end{tabular}

See footnote to table 3 for details.

TABLE 8

Height. Analysis of variance of the interpopulation data

\begin{tabular}{|c|c|c|}
\hline Souce & d.f. & M.S. \\
\hline$a$ & 4 & $794 \cdot 32 * * *$ \\
\hline$b_{1}$ & 1 & $595 \cdot 40 * * *$ \\
\hline$b_{2}$ & 4 & $84 \cdot 56$ \\
\hline$b_{3}$ & 5 & $46 \cdot 12$ \\
\hline Total (between families) & 14 & $310 \cdot 12 * * *$ \\
\hline Sets & 3 & $305 \cdot 21 * * *$ \\
\hline Blocks & 1 & $91 \cdot 98$ \\
\hline Sets $\times a$ & 12 & $101 \cdot 20 * *$ \\
\hline Sets $\times b_{1}$ & 3 & $103 \cdot 01$ \\
\hline Sets $\times b_{2}$ & 12 & $29 \cdot 61$ \\
\hline Sets $\times b_{3}$ & 15 & $117 \cdot 26 * * *$ \\
\hline Sets $\times$ Total & 42 & $86 \cdot 62 * * *$ \\
\hline Block interactions & 59 & $40 \cdot 31$ \\
\hline Duplicate plots & 119 & $43 \cdot 67$ \\
\hline Grand total & 238 & $69 \cdot 60$ \\
\hline
\end{tabular}

that there are additive differences in other populations too, though again their magnitude is insufficient to permit their detection. Indeed, for what this is worth, the $a$ mean squares of both the S4 and S5 diallel families are only just short of significance at the 5 per cent. level. These populations, therefore, appear to be polymorphic for height too. 


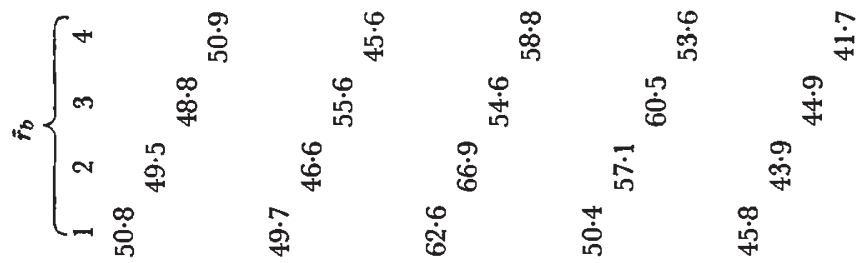

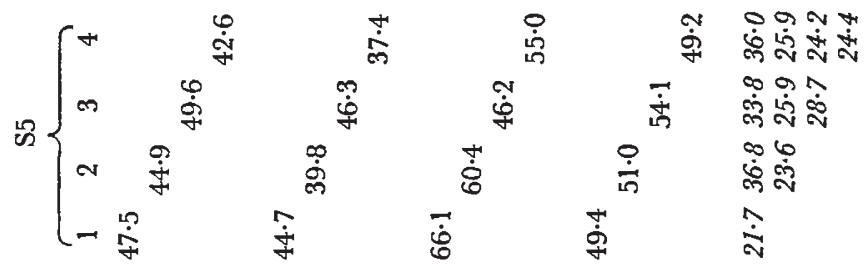

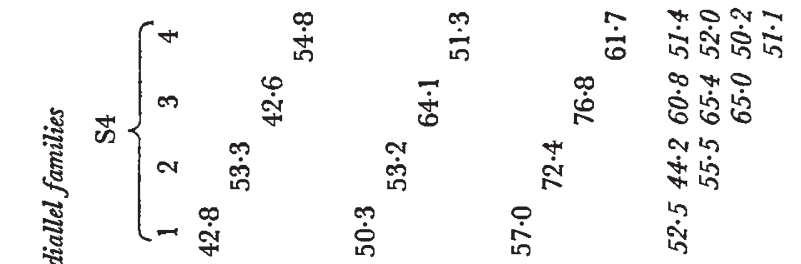

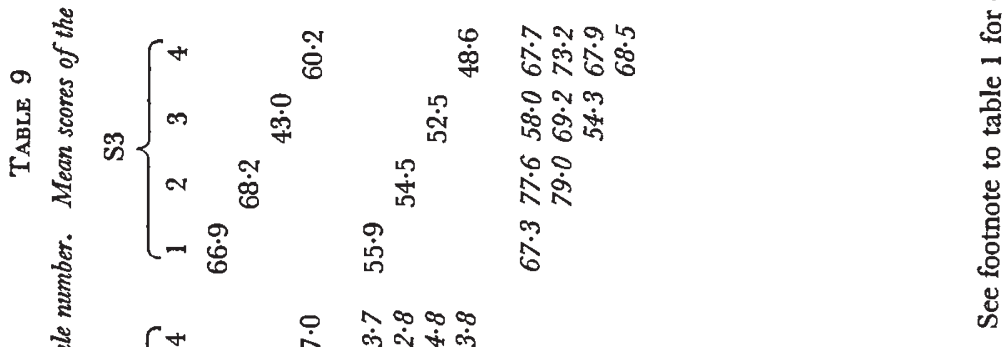

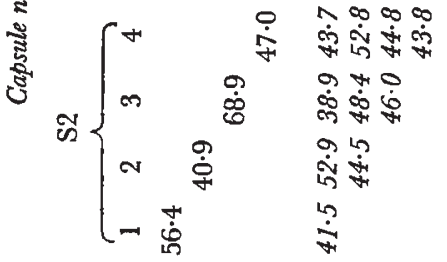

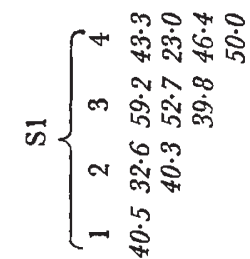

$$
\begin{aligned}
& \text { rent rama rant tama tama } \\
& \text { ज है है मे हू }
\end{aligned}
$$


The second point about this reanalysis of the interpopulation data is that that $b_{1}$ mean square also retains its significance. As in the original data, this is due to the fact that hybrid progeny are a little taller than their selfed contemporaries. Yet there is no evidence of significant potence in any of the intrapopulation data. Furthermore, S2 apart, their hybrid progeny are consistently shorter than their selfed progeny. The potence which can be detected in the interpopulation families must, therefore, be a property of genes which have been fixed in the populations. Having argued earlier that this trait is subject to long-term directional selection, such an outcome is to be expected, selection having been for increased stature. Selection has fixed, therefore, favourable dominant genes, though clearly different genes have been fixed in different populations.

\section{(iv) Capsule number}

Table 9 shows the mean capsule numbers of the diallel families and tables 10 and 11 the analysis of these data. Individual plants in natural

TABLE 10

Capsule number. Analyses of variance of the intrapopulation diallel families

\begin{tabular}{|c|c|c|c|c|c|c|}
\hline \multirow[b]{2}{*}{ Source } & \multirow[b]{2}{*}{ d.f. } & \multicolumn{5}{|c|}{ Population } \\
\hline & & $\mathrm{SI}$ & $\mathrm{S} 2$ & $\mathrm{~S} 3$ & $\mathrm{~S} 4$ & $\widehat{\mathrm{S} 5}$ \\
\hline$a$ & 3 & $270 \cdot 5$ & $74 \cdot 2$ & $621 \cdot 4$ & $344 \cdot 1$ & $32 \cdot 5$ \\
\hline$b_{1}$ & 1 & 0.5 & $86 \cdot 8$ & $26 \cdot 4$ & $39 \cdot 1$ & $327 \cdot 4$ \\
\hline$b_{2}$ & 3 & $888 \cdot 7 *$ & $127 \cdot 3$ & $7 \cdot 5$ & $20 \cdot 4$ & $219 \cdot 7$ \\
\hline$b_{3}$ & 2 & $165 \cdot 3$ & $22 \cdot 6$ & $104 \cdot 2$ & $285 \cdot 2$ & $2 \cdot 5$ \\
\hline Total (between families) & 9 & $423 \cdot 2$ & $81 \cdot 8$ & $235 \cdot 7$ & $189 \cdot 2$ & $121 \cdot 0$ \\
\hline Blocks & 1 & $966 \cdot 3$ & $319 \cdot 2$ & $1500 \cdot 6 *$ & $112 \cdot 9$ & $219 \cdot 5$ \\
\hline Block interactions & 9 & $292 \cdot 2$ & $359 \cdot 5$ & $13 \mathrm{I} \cdot 4$ & $191 \cdot 2$ & $166 \cdot 7 *$ \\
\hline Duplicate plots & 20 & $180 \cdot 9(19)$ & $298 \cdot 0$ & $255 \cdot 2(16)$ & $206 \cdot 2$ & $54 \cdot 0$ \\
\hline Grand total & 39 & $295 \cdot 3(38)$ & $262 \cdot 9$ & $253.9(35)$ & $196 \cdot 4$ & $99 \cdot 7$ \\
\hline
\end{tabular}

See footnote to table 3 for details.

populations of the species may vary widely with respect to the number of capsules they bear, numbers from one to over two hundred having been observed. The number shown in table 9 thus fall well within the natural range.

The population genetics of this trait is very straightforward. Firstly, there is almost no evidence of any heritable variation within populations either directly, from the entries of table 10, or indirectly, from those concerning the set interactions of table 11. Secondly, there are large differences between populations. The Polish material, S5, bears the lowest average number of capsules, 28.1; the two Scottish populations (S1 and S2) have intermediate number, 42.8 and 45.7 ; and the pair of Midland populations, S3 and S4, bear the largest number of 68.3 and 54.8 respectively. Thirdly, the genes which determine this trait display both additive and dominance effects. Dominance is incomplete and acts, as expected, in an increasing direction, the interpopulation hybrids bearing on average 6.3 capsules more than their selfed relatives. $W r / V r$ analysis shows, furthermore, that the points lie on a straight line of unit slope and that S5 parents carry the 
greatest number of recessive alleles. There is little to choose between the remaining four populations for their points comprise a group near the origin, i.e. they appear to contribute the same number of dominant alleles to their offspring.

TABLE 11

Capsule number. Analysis of variance of the interpopulation data

\begin{tabular}{|c|c|c|}
\hline Source & d.f. & M.S. \\
\hline$a$ & 4 & $5171 \cdot 1 * * *$ \\
\hline$b_{1}$ & 1 & $2112 \cdot 2 * *$ \\
\hline$b_{2}$ & 4 & $294 \cdot 8$ \\
\hline$b_{3}$ & 5 & $340 \cdot 8$ \\
\hline Total (between families) & 14 & $1834 \cdot 3 * * *$ \\
\hline Sets & 3 & $74 \cdot 4$ \\
\hline Blocks & 1 & $8204 \cdot 0 * * *$ \\
\hline Sets $\times a$ & 12 & $363 \cdot 4$ \\
\hline Sets $\times b_{1}$ & 3 & $87 \cdot 4$ \\
\hline Sets $\times b_{2}$ & 12 & $115 \cdot 8$ \\
\hline Sets $\times b_{3}$ & 15 & $179 \cdot 2$ \\
\hline Sets $\times$ Total & 42 & $207 \cdot 2$ \\
\hline Block interactions & 59 & $191 \cdot 2$ \\
\hline Duplicate plots & 119 & $276 \cdot 1$ \\
\hline Grand total & 238 & $365 \cdot 3$ \\
\hline
\end{tabular}

4. Discussion

(a) Summary of results

The chief purpose of the investigation described here and in previous papers was an exploratory one; that is, it was designed to provide some basic information about the population genetics of the species. We can now consider this information in the light of what it tells us about the impact of natural selection on this species. It is convenient to do this in terms of five questions which were in mind when the investigation was begun. Firstly, are the traits heritable? Secondly, given that they are, how is their genetical variation distributed between populations? Is most of this variation confined to differences within, rather than between, populations or is it distributed more equitably? Thirdly, do some populations possess more genetical variation for a particular trait than others? If so, what is the cause for this state of affairs? Fourthly, what are the heritabilities of the traits? Fifthly, what is their genetical architecture? Are they determined by genes whose chief effects are additive or is dominance also an important source of variance?

A summary of the chief statistics that we require for this enquiry is shown in tables 12 and 13.

(i) Are the traits heritable?

There is no doubt that all four traits are indeed heritable, since the analysis of each indicates unambiguous evidence of genetical variation. It 
TABLE 12

Population means and variance components

\begin{tabular}{|c|c|c|c|c|c|c|}
\hline \multirow[b]{2}{*}{ Character } & \multirow[b]{2}{*}{ Statistic } & \multicolumn{5}{|c|}{ Population } \\
\hline & & S1 & S2 & S3 & S4 & S5 \\
\hline \multirow[t]{4}{*}{ FT } & $\bar{x}$ & $39 \cdot 0$ & $29 \cdot 6$ & $38 \cdot 7$ & $36 \cdot 4$ & $21 \cdot 3$ \\
\hline & $\sigma_{b}^{2}$ & $0 \cdot 4$ & $37 \cdot 5 * * *$ & $30 \cdot 4 * * *$ & $16 \cdot 8 * * *$ & $9 \cdot 5 * * *$ \\
\hline & $\sigma_{w}^{2}$ & $30 \cdot 6$ & $16 \cdot 5$ & $14 \cdot 0$ & $22 \cdot 2$ & $17 \cdot 1$ \\
\hline & $t^{\omega}$ & $1 \%$ & $59 \%$ & $68 \%$ & $43 \%$ & $36 \%$ \\
\hline \multirow[t]{4}{*}{ SR } & $\bar{x}$ & 6.48 & $6 \cdot 27$ & 6.94 & $7 \cdot 01$ & $6 \cdot 63$ \\
\hline & $\sigma_{b}^{2}$ & $0.053 * *$ & $0.322 * * *$ & $0.022 *$ & $0 \cdot 101 * * *$ & $0.313 * * *$ \\
\hline & $\sigma_{w}^{2}$ & $0 \cdot 161$ & $0 \cdot 123$ & $0 \cdot 115$ & $0 \cdot 114$ & 0.287 \\
\hline & $t$ & $25 \%$ & $72 \%$ & $16 \%$ & $47 \%$ & $52 \%$ \\
\hline \multirow[t]{4}{*}{$\mathrm{HT}$} & $\bar{x}$ & $19 \cdot 1$ & $26 \cdot 1$ & $25 \cdot 9$ & $23 \cdot 8$ & $23 \cdot 3$ \\
\hline & $\sigma_{b}^{2}$ & 1.68 & $1.39 *$ & -0.39 & 0.52 & $1 \cdot 70$ \\
\hline & $\sigma_{w}^{2}$ & $4 \cdot 50$ & $3 \cdot 19$ & $3 \cdot 18$ & $3 \cdot 49$ & $12 \cdot 67$ \\
\hline & $t$ & $27 \%$ & $30 \%$ & $0 \%$ & $13 \%$ & $12 \%$ \\
\hline \multirow[t]{4}{*}{$\mathrm{CN}$} & $\bar{x}$ & $42 \cdot 8$ & $45 \cdot 7$ & $68 \cdot 3$ & $54 \cdot 8$ & $28 \cdot 1$ \\
\hline & $\sigma_{b}^{2}$ & 52 & -59 & 6 & -3 & 8 \\
\hline & $\sigma_{w}^{2}$ & 217 & 317 & 211 & 202 & 89 \\
\hline & $t$ & $19 \%$ & $0 \%$ & $3 \%$ & $0 \%$ & $8 \%$ \\
\hline
\end{tabular}

The components, $\sigma_{b}^{2}$ and $\sigma_{w}^{2}$, have been obtained from each intrapopulation diallel set by simply partitioning their variance into a mean square measuring differences between families $\left(\mathrm{MS}_{1}\right)$ and another concerning differences within them $\left(\mathrm{MS}_{2}\right)$. Thus $\mathrm{MS}_{1}=\sigma_{v}^{2}+k \sigma_{b}^{2}$, where $k=8$ in the case of flowering time (FT) and ray number (SR) and 4 for height (HT) and capsule number (CN). The values of the intra-class correlation coefficient, $t$, are shown as percentages $\left(t=\sigma_{b}^{2} /\left(\sigma_{b}^{2}+\sigma_{w}^{2}\right)\right)$.

\section{TABLE 13}

Variance components of the interpopulation diallel data, the grand total variance of which has been partitioned into three items which measure respectively (i) variation between populations; (ii) variation between families within populations; and (iii) variation between plants within families and populations

\begin{tabular}{|c|c|c|c|c|}
\hline \multirow[b]{2}{*}{ Statistic } & \multicolumn{4}{|c|}{ Character } \\
\hline & FT & $\mathrm{SR}$ & $\mathrm{HT}$ & $\mathrm{CN}$ \\
\hline 3 & $25.0(43 \%) * * *$ & $0.010(2 \%)$ & $2 \cdot 17(21 \%)^{* *}$ & $100(29 \%)^{* * *}$ \\
\hline$\sigma b$ & $12 \cdot 6(22 \%)^{* * *}$ & $0.259(57 \%) * * *$ & $1.77(17 \%) * * *$ & - \\
\hline$\sigma_{n}^{2}$ & $20 \cdot 1(35 \%)$ & $0.182(41 \%)$ & $6.37(62 \%)$ & $239(71 \%)$ \\
\hline
\end{tabular}

The expected composition of these mean squares is thus:

$$
\begin{aligned}
& \mathrm{MS}_{1}=\sigma_{w}^{2}+4 \sigma_{b}^{2}+16 \sigma_{p}^{2} \\
& \mathrm{MS}_{2}=\sigma_{w}^{2}+4 \sigma_{b}^{2} \\
& \mathrm{MS}_{3}=\sigma_{w}^{2}
\end{aligned}
$$

The data from which the estimates shown in the table were obtained was that from the first experiment in which all four sets of crosses were grown. 
is, of course conceivable, that these genetical differences are due simply to chance (i.e. drift). It is unlikely, however, that this is true of all four traits. Rather, these differences are caused by the effects of natural selection in these populations; that is, these traits are not trivial ones and are worth, therefore, further consideration.

\section{(ii) Distribution of variance}

The traits vary considerably in respect of their distribution of variance within and between populations. Thus, for capsule number, though their means differ, there is no evidence of any heritable variation within any of the populations. On the other hand, for stigmatic ray number, virtually all variance concerns differences between plants within, rather than between, populations. Each of these populations is also polymorphic for flowering time. Though there is no evidence of any heritable variation in the $\mathrm{Sl}$ data shown here, which concerns the $\mathrm{F}_{1}$ generation families only, there was plenty among the $\mathrm{F}_{2}$ generation families of this anomalous population (see Lawrence, 1965). Unlike ray number, however, no less than 43 per cent. of the variance of flowering time concerns differences between populations. Height is less easy to classify in this respect. We have seen that there is little direct evidence of heritable variation within populations, apart from S2, for this character. At the same time, the evidence from the analysis of the interpopulation families suggested that other populations are polymorphic for this trait too. Thus if this interpretation is correct, since there are also differences between populations in respect of their average stature, height appears to have a similar distribution of variance to that of flowering time. It turns out, therefore, that these populations are polymorphic for three of the four traits which have been examined and that for two of them, flowering time and height, this internal differentiation has been accompanied by divergence between the populations. Furthermore, it can be argued that we do not expect a fitness trait, such as capsule number, to display polymorphism, since on a simple view, maximum expression of such traits is always advantageous.

Now we have, at present, no information on the nature of the environmental differences, hence the selective forces, which maintain any of these polymorphisms or those which have caused divergence between populations, assuming that the latter might differ from the former. Nevertheless, it is clear that these forces have had a directional impact on all of the characters except ray number. In the short term, however, as Mather (1960) has pointed out, selection is more likely to be stabilising in its effects. It is for this reason, that we presumably find that flowering time, ray number and height are polymorphic traits in these populations.

\section{(iii) Amount of variance}

It is less easy to answer this question, concerning whether the populations differ in respect of the amount of genetical variation they possess, than the two previous questions. On the one hand, we have examined the progenies of only four plants in each population, a number which is clearly smaller than desirable. On the other hand, the detection of differences between second-degree statistics is more difficult than the comparable task with, say, sample means. We cannot expect the present data to be very informative 
on this question, therefore, though where it is possible to detect such differences, it is not unreasonable to take them at their face value.

Two mean squares of the analysis of the intrapopulation diallel families have been examined with this in mind. One of these is the Total (between families) mean square $\left(\mathrm{MS}_{1}\right)$ of these analyses; the other is the pooled within-families item $\left(\mathrm{MS}_{2}\right.$; see table 12 for further details). There is, of course, no point in considering capsule number, for which the populations have no heritable variance.

Both mean squares are just heterogeneous over populations with respect to their variance for flowering time. This is due entirely, however, to the extreme values of the anomalous statistics of the $\mathrm{S} 1$ population, which, for reasons that have been given earlier, we are obliged to disregard. On the present evidence, therefore, the populations appear to be uniformly polymorphic for flowering time.

They are not, however, for either ray number or height, both mean squares of both of these traits being heterogeneous over populations. While for both traits, the heterogeneity of their $\mathrm{MS}_{2}$ 's is due to the large value of the $\mathrm{S} 5$ estimates, that of the $\mathrm{MS}_{1}$ 's is not (nor are ray number and height correlated in this population).

We have seen that the populations are polymorphic with respect to ray number and height. We can now see that the populations are not uniformly polymorphic for these traits, the extent of the polymorphism in some being greater than that of others. Whether these differences reflect variation in the absolute amounts of genetical variation possessed by these populations, such as might be caused by differences in their size or the degree to which their habitats are heterogeneous, we cannot at present say. Since, however, the heterogeneity of the $\mathrm{MS}_{1}$ 's for both ray number and height appears to be partly independent of that of their corresponding $\mathrm{MS}_{2}$ 's, it is more likely that these differences reflect differences in population structure, such as might be caused by different degrees of inbreeding. These possibilities clearly merit further investigation.

\section{(iv) Heritability}

We are obviously unable to attempt much more than a qualitative answer to the question of the heritability of these traits, both because the size of the experiment is insufficient to provide good estimates of heritability; and because we no not know the breeding system of this self-compatible species. For these reasons we have not attempted to partition the variance of these traits into their causal components, as was done with the more extensive flowering time data when this was considered on its own (Lawrence, 1965). The present inquiry is limited, therefore, to the examination of two observational components of variance, $\sigma_{b}^{2}$ and $\sigma_{v}^{2}$, which have been calculated from the mean squares we have just been considering, $\mathrm{MS}_{1}$ and $\mathrm{MS}_{2}$; and to the statistic, $t$ (the intra-class correlation coefficient) which may be obtained from them.

Despite these difficulties, it turns out that the traits can be easily ranked with respect to their heritability, providing, that is, we care to assume that the mating system for each is the same (i.e. no assortative mating). From the $t$ values shown in table 12, it is clear that capsule number has, as we expect, the lowest and flowering time the highest heritability, height and ray number being intermediate to these in that order. 
The actual heritabilities are almost certainly higher than these values of $t$, since it is unlikely that $P$. dubium is a completely inbreeding species. Though seed can be readily obtained by manual self-pollination in this species, its flowers are vigorously foraged by bees if not protected. Under natural conditions, therefore, seed is likely to result from a mixture of self and of cross-pollination. The individuals in the present families are, of course, full-sibs. Thus the heritability of a trait cannot be greater than twice the intraclass correlation coefficient, $t$, nor less than the value of the latter statistic itself; in other words, though we are unable to obtain a precise estimate of $h^{2}$ in the present circumstances, we can at least set bounds on its value. Thus by averaging $t$ over populations for each trait in turn we find that for flowering time the heritability falls within the range 50-100 per cent.; for ray number, 42-84 per cent.; and for height 16-32 per cent. Both flowering time and ray number have high heritabilities, which means that, in practical terms, these should be rather easier characters to handle than height, in that for a given precision they require smaller experiments than the latter. These results also suggest that it is important for natural populations to maintain rather more genetical variation in respect of flowering time and ray number than for height. In short the polymorphisms of the former characters are better defined than that of the latter. We do not of course know, however, how much of this variation survives the hazards of germination and establishment in the natural habitats of the species.

\section{(v) Genetical architecture}

We have seen that the genes which determine each of these four traits have similar properties, in that they display both additive and non-additive effects. Furthermore, where it has been appropriate, $W r / V r$ analysis have revealed little evidence of non-allelic interaction with respect to any of these characters in these data. It is probable, therefore, that non-additive effects are due mainly, if nor entirely, to dominance rather than to epistasis. This dominance is incomplete and is for early flowering, low ray number, high stature and high capsule number respectively.

The genetical architecture of these characters is thus consistent with our previous conclusions about the effects of selection on these traits. If selection on flowering time, ray number and height is in the short term, at least, stabilising, then we do not expect to find evidence in the intrapopulation data of strong, directional dominance or epistasis (Mather, 1960; Kearsey and Kojima, 1967). On the other hand, the evidence from the interpopulation crosses that favourable dominant genes have been fixed in some of the populations with respect to flowering time and height may be taken as an indication that these characters have, in the long term at least, been subject to some directional selection.

The genetical architecture of capsule number is not, however, consistent with our earlier conclusions about the type of selection to which this trait has been subject. We have, of course, no evidence of heritable variation within populations for this character, but that from the interpopulation crosses shows quite clearly that dominance is incomplete. The impact of selection on capsule number appears, therefore, to have been less relentlessly directional that it has evidently been on viability (Breese and Mather, 1960), egg hatchability (Kearsey and Kojima, 1967) or on yield of progeny (Barnes, 1968) in Drosophila melanogaster, for example. On the other hand, its effects 
have apparently been far from negligible, since selection has exhausted the genetical variation within these populations.

Now we have assumed, of course, that this trait is subject to directional selection, because it is a component of fitness. It doesn't follow from this, however, that the relationship between capsule number and fitness is linear over the entire range of expression of the former. What matters to the species in terms of fitness is the total quantity of viable seed produced. The yield of viable seed produced by a plant with a very large number of capsules could be less than that produced by another with a smaller number of larger capsules. If the optimum number of capsules is high, we might in practice rarely observe the entire range of expression of the trait, so that the character would appear to be subject to directional selection. Yet consideration of the whole range of expression would show that, on the scale of measurement used, the character was in fact subject to asymmetrical stabilising selection. Robertson (1955), who has discussed the relationship between characters and fitness, has argued that only a small proportion of the genetical variation of traits closely related to fitness can be expected to be additive and that, accordingly, they can be expected to show inbreeding depression. The advantage of this hypothesis is, of course, that it can be examined in future experiments.

Capsule number also appears to be subject to geographical variation, though none of the other characters studied here are. Thus the Polish population, S5, has the lowest average capsule number; the two Midland populations, S3 and S4, have the highest; and the pair of Scottish populations, $\mathrm{S} 1$ and $\mathrm{S} 2$, an intermediate average number.

\section{(b) Concluding remarks}

At a number of places in the preceding discussion we have had to be rather more cautious in drawing conclusions from the data than is desirable. Because of the small size of the component parts of the experiment (the intrapopulation diallel crosses, for example), some of the estimates of statistics of interest had a very large sampling variance. On the other hand, though the size of these parts is small, the overall size of the experiment is not. It will be recalled that the experiment takes the form of a $20 \times 20$ partial diallel design, which entailed the raising of 110 families of selfs and crosses and nearly 4800 plants. The size of the experiment as such, therefore, is not the problem here. The difficulty arises from the compromise that has always to be made in investigations of this type, which is whether to sample a small number of plants from a large number of populations or vice versa. Both, of course, can be increased if one is prepared to forgo genetical information. Similarly, it is possible to increase the number of plants sampled from a population if one is prepared to examine only one. To have done this, however, would have been to sacrifice the inferential basis which information from five populations is able to provide. Nevertheless, future investigation of the population genetics of this species will have to be designed so as to obtain better information than this preliminary investigation is capable of providing.

The second point worth making in conclusion concerns the characters that have been examined and the species we have chosen to study. Now there is no doubt that a major advance of our knowledge of the effects of selection in natural populations has come from the study of contrasting forms 
such as melanism in moths (Kettlewell, 1957), and of heavy-metal tolerance in grasses (Bradshaw, McNeilly and Gregory, 1965). Most of the variation which is encountered in natural populations of animals and plants, however, is not of this type, many, rather than a few, "morphs" being the rule. Nor is this variation so extreme as to advertise its presence prior to analysis of the situation. We cannot, for these reasons, be sure, therefore, that the information from studies of contrasting forms is a reliable guide to the genetics of populations in general. What is required is information from the more common situation, with which to complement that from these special ones. It was for these reasons that the present species and the present characters were chosen for investigation.

\section{Summary}

1. Samples from five natural populations of Papaver dubium have been investigated in respect of three further metrical characters, stigmatic ray number, height and capsule number.

2. Four plants from each sample were crossed in such a way as to provide a set of diallel families within each population (the intrapopulation crosses), as well as four sets of diallel families between populations (the interpopulation crosses). Taken together the two types of crosses comprise a $20 \times 20$ partial diallel design.

3. The populations were polymorphic for ray number and probably also for height. No evidence of any heritable variation was found within populations for capsule number.

4. The populations differed with respect to their average stature and capsule number, but not for their ray number.

5. The populations also appear to differ with respect to their genetical structure for ray number and for height.

6. The genetical architecture of these characters and of flowering time is consistent with the view that each has in the short term been subject to stabilising selection. In the long term, flowering time, height and capsule number have also been subject to directional selection and there is some evidence that favourable dominant genes have been fixed in at least some populations with respect to these characters.

Acknowledgments.-My thanks are due to those past members of the department who assisted with the scoring of the material; to the staff of the S.R.C. Atlas Computer Laboratory at Chilton where most of the data was analysed; and to my colleagues, Drs Barnes, Gale and Kearsey, who made a number of helpful suggestions about the interpretation and presentation of the results.

\section{REFERENGES}

BARNES, B. W. 1968. Maternal control of heterosis for yield in Drosophila melanogaster Heredity, 23, 563-572.

BARNES, B. W., AND KEARSLEY, м. J. 1970. Variation for metrical characters in Drosophila populations. I. Genetic analysis. Heredity, 25, 1-10.

BRADSHAW, A. D., MCNEILLY, T. S., AND GREGORY, R. P. G. 1965. Industrialisation, evolution and the development of heavy metal tolerance in plants. Ecology and the Industrial Society, 5th Brit. Ecol. Soc. Symp., pp. 327-343. Blackwell, Oxford.

BREESE, E. L., AND MATHER, K. 1960. The organisation of polygenic activity within a chromosome in Drosophila. II. Viability. Heredity, 14, 375-399. 
Clapyam, A. R., TUtin, T. G., AND WARbURG, E. F. 1962. Flora of the British Isles. Cambridge University Press.

DICKInson, A. G., AND JINKs, J. L. 1956. A generalised analysis of diallel crosses. Genetics, 41, 65-78.

FORD, E. B. 1940. Polymorphism and taxonomy in The New Systematics (ed. Julian Huxley), pp. 493-513. Clarendon Press, Oxford.

HAYMAN, B. I. 1954. The analysis of variance of diallel tables. Biometrics, 10, 235-244.

JINks, J. L. 1954. The analysis of continuous variation in a diallel of Nicotiana rustica varieties. Genetics, 39, 767-788.

JONES, R. M. 1965. The analysis of variance of the half-diallel table. Heredity, 20, 117-121. KEARSEY, M. J. 1970. Experimental sizes for detecting dominance variation. Heredity, 25, 542-592.

KEARSEY, M. J., AND KOJIMA, K. 1967. The genetic architecture of body weight and egg hatchability in Drosophila melanogaster. Genetics, 56, 23-37.

KETTLEWELL, H. B. D. 1957. The contribution of industrial melanism in the Lepidoptera to our knowledge of evolution. Adv. Sci., 52, 245-52.

LAWRENGE, M. J. 1965. Variation in wild populations of Papaver dubium. I. Variation within populations; diallel crosses. Heredity, 20, 183-204.

LAWRENCE, M. J. 1969. Variation in wild populations of Papaver dubium. II. Variation between populations. Heredity, 24, 337-346.

MGNaUghton, I. M., AND harper, J. L. 1964. Biological Flora of the British Isles. No. 99. Papaver L. 7. Ecol., 52, 767-793.

MAther, K. 1960. Evolution in polygenic systems. Evoluzione e Genetica, Accad. Nazionale die Lincei, 47, 131-152.

RobertSon, A. 1955. Selection in animals; synthesis. Cold Spr. Harb. Symp. Quant. Biol., 20, 225-229 